\title{
Corrigendum to "Expanding Thermal Plasma Chemical Vapour Deposition of ZnO:Al Layers for CIGS Solar Cells"
}

\author{
K. Sharma, ${ }^{1}$ B. L. Williams, ${ }^{1}$ A. Mittal, ${ }^{1}$ H. C. M. Knoops, ${ }^{1}$ B. J. Kniknie, ${ }^{2,3}$ N. J. Bakker, ${ }^{3,4}$ \\ W. M. M. Kessels, ${ }^{1,3}$ R. E. I. Schropp, ${ }^{1,3,4}$ and M. Creatore ${ }^{1,3}$ \\ ${ }^{1}$ Department of Applied Physics, Eindhoven University of Technology, P.O. Box 513, 5600 MB Eindhoven, The Netherlands \\ ${ }^{2}$ TNO, P.O. Box 6235, 5600 HE Eindhoven, The Netherlands \\ ${ }^{3}$ Solliance, High Tech Campus 21, 5656 AE Eindhoven, The Netherlands \\ ${ }^{4}$ ECN, High Tech Campus 21, 5656 AE Eindhoven, The Netherlands
}

Correspondence should be addressed to K. Sharma; k.sharma@tue.nl

Received 24 November 2014; Accepted 16 February 2015

Copyright (C) $2015 \mathrm{~K}$. Sharma et al. This is an open access article distributed under the Creative Commons Attribution License, which permits unrestricted use, distribution, and reproduction in any medium, provided the original work is properly cited.

In the paper titled "Expanding Thermal Plasma Chemical Vapour Deposition of ZnO:Al Layers for CIGS Solar Cells," in the third paragraph in Experimental, some errors have occurred and it should be corrected as follows: “The $\mathrm{ZnO}: \mathrm{Al}$ deposition parameters of the two conditions used here are shown in Table 1. All parameters were kept constant except for the Ar flow rate, whether or not a He back flow (directed from the backside of the heater to the substrate) was used to increase the thermal contact between the substrate and the holder. For both conditions, preliminary growth runs were made to check the final temperature $\left(T_{\mathrm{f}}\right)$ reached following 12 minutes of $\mathrm{ZnO}: \mathrm{Al}$ deposition, using temperature-sensitive stickers mounted on the samples. Since a higher final temperature was recorded when using $1 \mathrm{slm} \mathrm{Ar}$ in the absence of He backflow $\left(T_{\mathrm{f}}=240^{\circ} \mathrm{C}\right)$, this condition is denoted as the high thermal budget condition (HTB), whereas the use of $1.5 \mathrm{slm} \mathrm{Ar}$ combined with $\mathrm{He}$ backflow $\left(T_{\mathrm{f}}=175^{\circ} \mathrm{C}\right)$ is denoted by the low thermal budget (LTB) condition. In both cases the temperature increased linearly with time from the set-point of $100^{\circ} \mathrm{C}$. For longer deposition times, final temperature values were extrapolated assuming the linear increase in temperature with deposition time. Furthermore, the HTB condition yielded much slower growth rates (0.35$0.38 \mathrm{~nm} / \mathrm{s})$ than the LTB condition $(0.9-1.0 \mathrm{~nm} / \mathrm{s})$, so longer deposition times (and therefore greater thermal budget) were necessary in the former case to accumulate comparable film thicknesses." 

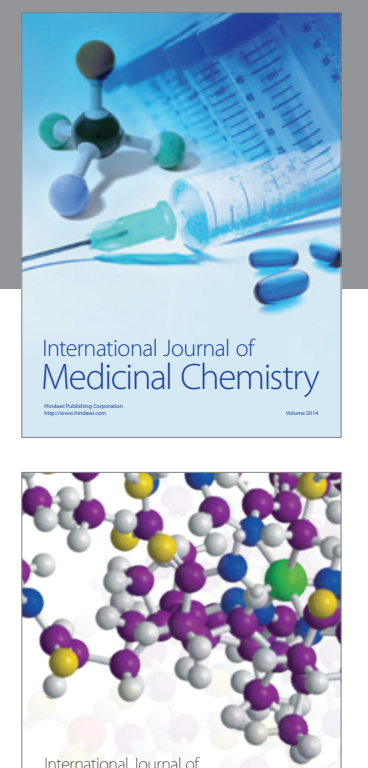

\section{Carbohydrate} Chemistry

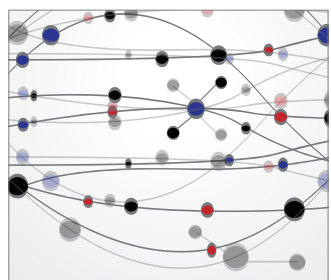

The Scientific World Journal
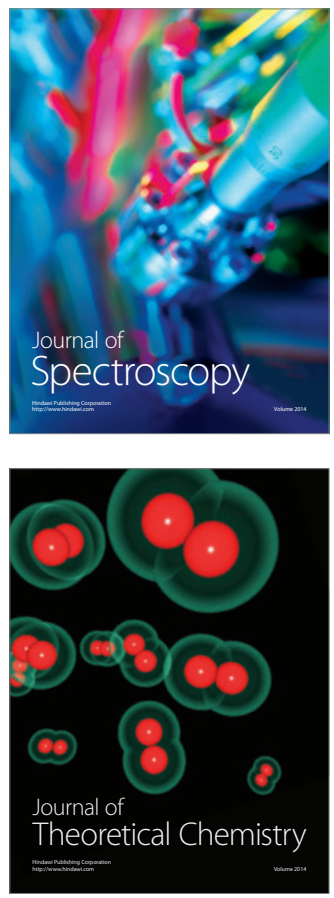
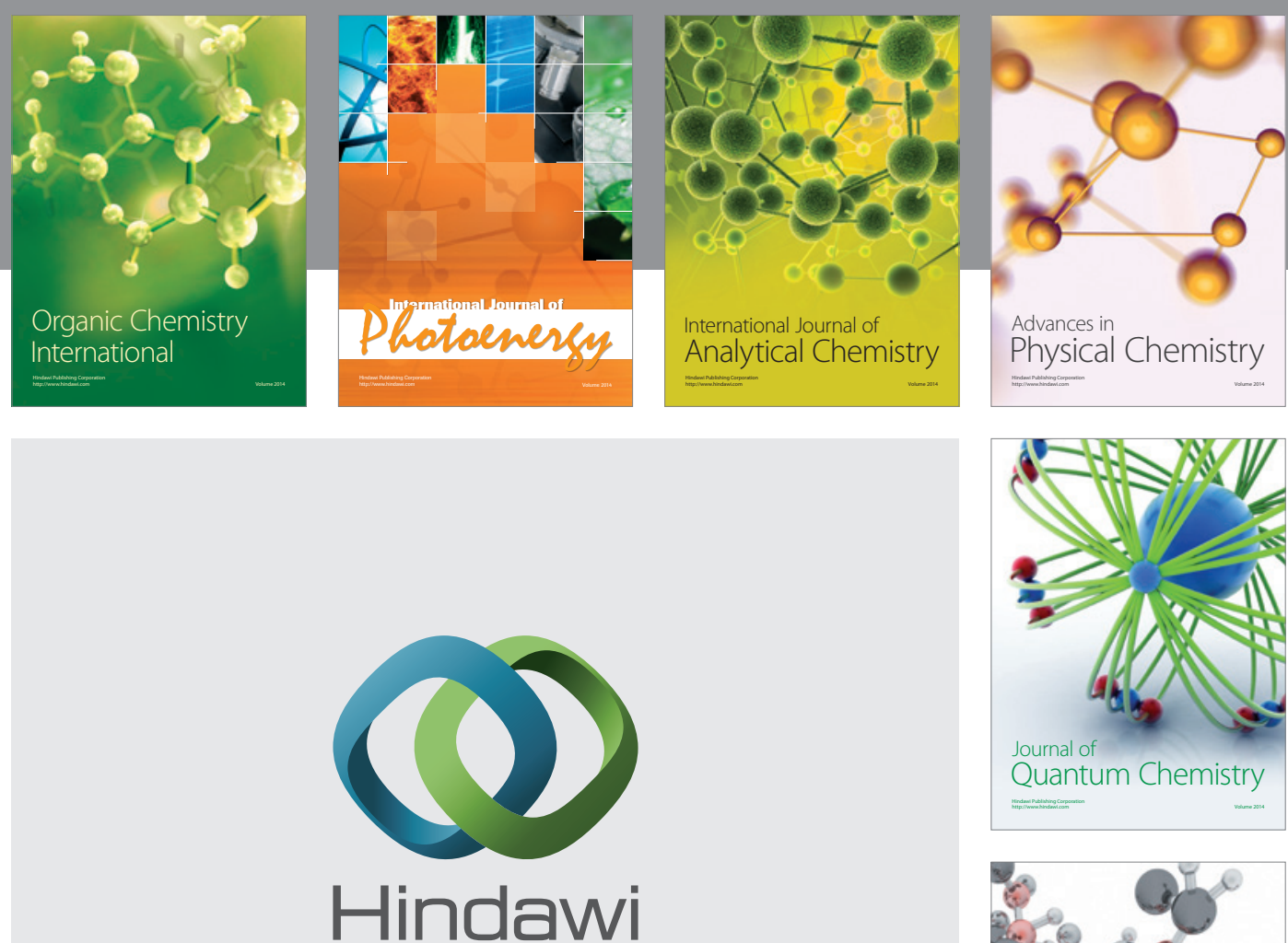

Submit your manuscripts at

http://www.hindawi.com

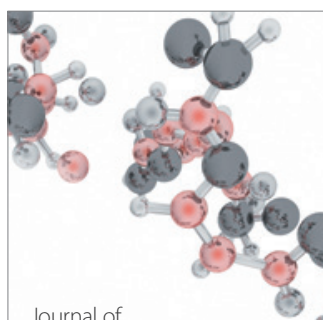

Analytical Methods

in Chemistry

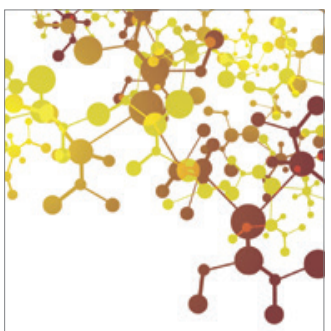

Journal of

Applied Chemistry

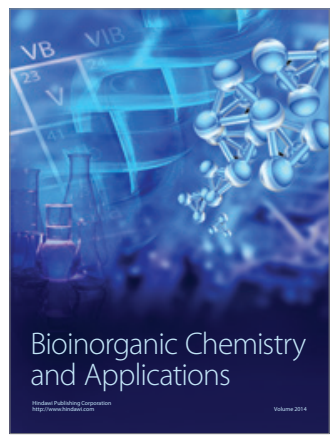

Inorganic Chemistry
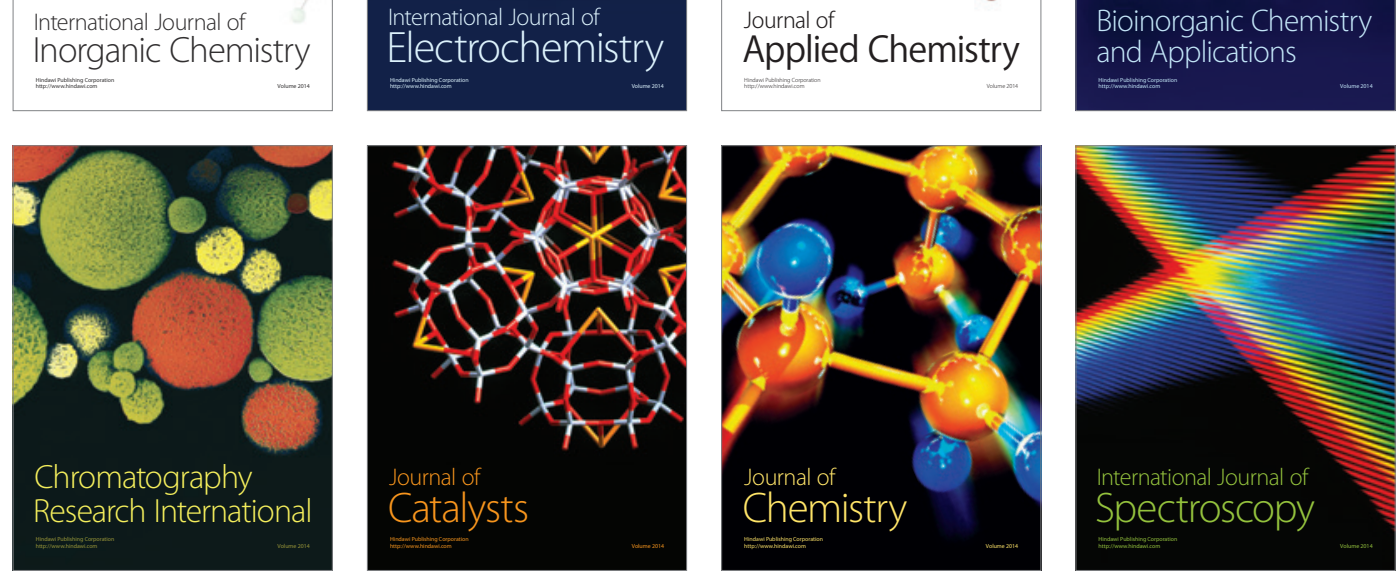